\title{
Last Mile Logistics in Mega-Cities for Perishable Fruits
}

\author{
Javier Arturo Orjuela-Castro' ${ }^{1}$, Juan Pablo Orejuela-Cabrera ${ }^{2}$ (D), Wilson Adarme-Jaimes ${ }^{3}$ (D) \\ ${ }^{1}$ Universidad Distrital Francisco José de Caldas (Colombia) \\ ${ }^{2}$ Facultad de Ingeniería, Universidad del Valle (Colombia) \\ ${ }^{3}$ Facultad de Ingeniería, Universidad Nacional de Colombia (Colombia) \\ jorjuela@udistrital.edu.co,juan.orejuela@correounivalle.edu.co,wadarmej@unal.edu.co
}

Received: October 2018

Accepted: May 2019

\begin{abstract}
:
Purpose: A common problem in mega cities is congestion, due to the size of the automotive park, this makes that the perishable foods decreasing their organoleptic characteristics or increases their losses, which requires considering the effect of time on routing problems. The state of the art demonstrates the need to formulate new routing models that include the specific characteristics of perishable foods in order to reduce their losses.
\end{abstract}

Design/methodology/approach: A mathematical model was formulated based on two classical models: the three-index vehicle flow model proposed by (Golden, Assad, Levy \& Gheysens, 1984) and the time window model proposed by (Cordeau, Desaulniers, Desrosiers, Solomon \& Soumis, 1999). We proposed a novel VRP Model that permits reductions loss due to the perishable.

Findings: The optimum cost is found with $\mathrm{AMP} \otimes$ for twenty nodes, six vehicles and six fruits. For more nodes, a two-phase strategy is proposed, first a clustering based on a modified p-median model and then a VRP for each cluster.

Research limitations/implications: The results showed the need to investigate multiobjective models, since the performance measures can be efficiency, quality and response capacity; the model can be applied in other supply chains of perishable foods.

Social implications: According to FAO in Logistics practices in the last mile generate between 10-30\% of the perishable food loss in developing countries' mega-cities.

Originality/value: A last-mile logistics strategy is proposed to manage delivery routes for fresh fruits in mega-cities, considering the effect of congestion through travel time in the perishability function. The new model it uses the flow variable to control the amount of each fruit arriving to each node and the time variable to define fruit waste or loss depending on the time and type of fruit.

Keywords: last mile logistics, mega-cities city logistics, perishable fruits

\section{To cite this article:}

Orjuela-Castro, J.A., Orejuela-Cabrera, J.P., \& Adarme-Jaimes, W. (2019). Last mile logistics in mega-cities for perishable fruits. Journal of Industrial Engineering and Management, 12(2), 318-327. https://doi.org/10.3926/jiem.2770 


\section{Introduction}

A city with more than five million inhabitants is considered a mega-city (Graizbord, 2007). There are around 85 mega-cities in the world which concentrate around 14\% of the world's population; 62 of them remain in developing countries and 8 in Latin America, among which is Bogotá. Mobility in mega-cities is highly dependent on transport (Graizbord, 2007) the large number of vehicles entails congestion (Thomsom \& Bull, 2001) which affects the speed of vehicles (Jabali, Van Woensel \& De Kok, 2012) and their travel time.

Food waste is the largest constituent of municipal solid waste in mega-cities (Cheng \& Lo, 2016). The case of fresh fruit routing in mega cities, the travel times are important since, depending on their duration and the characteristics of the fruit, losses are generated.

There are two different approaches for the determination of perishable costs of deterioration for perishable foods. The first proposes that all products become obsolete at the end of the planning period. The deterioration during the planning period is the second. This last approach can in turn be divided into two classes. The first has a specified shelf life, as with meat products. The second has a function of continuous decay, as with vegetables, fruits, flowers, live animals among others (Osvald \& Stirn, 2008). In this article we assume the second class of the second approach. In the literature there aren't studies that contemplate these approaches applied to the routing of vehicles, for the specific case of highly perishable foods.

One of the most common ways of managing perishability when formulating models is to establish the shelf life of the products as an intrinsic value of the cargo (Orjuela-Castro, Sepulveda-García \& Ospina-Contreras, 2016). In this way, as time passes, the product is degraded linearly towards the planning horizon (Rocha-Medina, González-La Rotta \& Orjuela-Castro, 2011).

In this paper, it is presented a VRP model for highly perishable foods, which includes a heterogeneous vehicle fleet, the fixed cost of transport, the variable cost per distance travelled and the cost for loss of fruit associated with transport time. It also takes into account the perishability of the fruit in an explicit relationship with the travel time and the vehicle capacity. A novel approach in VRP perishable food models.

This article is organized methodologically starting with the presentation of the designed model and its solution strategy. This is followed by the results and analysis, presented through the case study of distribution of highly perishable fruits in a mega-city, Bogota-Colombia. The article ends presenting the conclusions reached.

\section{Literature Review}

A summary of articles about VRP for perishable foods is provided in (Gong \& Fu, 2010; Rocha-Medina et al., 2011) take into account the perishability through the expiration date. (Osvald \& Stirn, 2008) propose that the linear dependence between quality and time is fixed; therefore, the lost total quantity is proportional to the quantity of product.

Among the authors with this approach are (Gong \& Fu, 2010), who manage perishability as a value connected to the time travelled by the perishables. In addition, the higher number of nodes that the products have to pass before being delivered, the higher value of perishability it will have. (Shamsi, Raisi \& Aftab, 2014) take a percentage of the shelf life, which restricts the level of consumer inventory in consecutive periods. (Govindan, Jafarian, Khodaverdi \& Devika, 2014; Kande, Prins, Belgacem \& Redon, 2015) on the other hand, work on the inventory-routing problem, they use the days on which inventory must be replenished.

Zhang and Chen (2014) manage perishability in a chain of frozen food products; the durability of the products depends on the breaking of the cold chain. They consider that strict control of temperature and delivery time is important for this type of chain. In their model, they consider the temperature differences produced by the loading or the delivery process generates unloading of vehicles, as well as it.

The problem of windows of time is the approach most used by researchers in VRP for the delivery of perishable foods. (Cheng, Hsueh \& Chang, 2009) consider production scheduling and vehicle routing with time windows for 
perishable food, The value of perishable food products will decay once they are produced, the products may have different decay rates, soft time windows are considered. Any vehicle that arrives late will incur a penalty, if arrives early has to wait until the beginning of the time window.

The specific articles of VRP in perishable food supply chains that are taken into account in the formulation of the models are presented in Table 1.

\begin{tabular}{|c|c|c|c|c|c|c|}
\hline \multirow[b]{2}{*}{$\begin{array}{l}\text { Variables and } \\
\text { parameters }\end{array}$} & \multicolumn{6}{|c|}{ Authors } \\
\hline & $\begin{array}{l}\text { Soysal, } \\
\text { Bloemhof- } \\
\text { Ruwaard, } \\
\text { Haijema and } \\
\text { van der Vorst } \\
\text { (2015) }\end{array}$ & $\begin{array}{l}\text { Gonzalez, } \\
\text { Adarme and } \\
\text { Orjuela } \\
\text { (2015); Chen, } \\
\text { Hsueh and } \\
\text { Chang (2009) }\end{array}$ & $\begin{array}{c}\text { Rahimi, } \\
\text { Baboli and } \\
\text { Rekik (2014); } \\
\text { Amorim, } \\
\text { Günther and } \\
\text { Almada-Lobo } \\
\text { (2012) }\end{array}$ & $\begin{array}{l}\text { Govindan, } \\
\text { Jafarian, } \\
\text { Khodaverdi } \\
\text { and Devika } \\
\text { (2014) }\end{array}$ & $\begin{array}{l}\text { Zhang and } \\
\text { Chen (2014) }\end{array}$ & $\begin{array}{l}\text { Golden, } \\
\text { Assad, Levy } \\
\text { and Gheysens } \\
\text { (1984); Song } \\
\text { and Ko (2016) }\end{array}$ \\
\hline ND & $\mathrm{X}$ & $\mathrm{X}$ & $\mathrm{X}$ & $\mathrm{X}$ & $\mathrm{X}$ & $\mathrm{X}$ \\
\hline $\mathrm{VC}$ & $x$ & $x$ & $X$ & & $\mathrm{X}$ & $x$ \\
\hline QV & $x$ & $\mathrm{X}$ & $x$ & $\mathrm{X}$ & $\mathrm{X}$ & $\mathrm{X}$ \\
\hline $\mathrm{TF}$ & $X$ & $x$ & $X$ & $\mathrm{X}$ & $\mathrm{X}$ & $\mathrm{X}$ \\
\hline $\mathrm{D}$ & $\mathrm{X}$ & $\mathrm{X}$ & & $\mathrm{X}$ & $\mathrm{X}$ & $\mathrm{X}$ \\
\hline DIS & $\mathrm{X}$ & $\mathrm{X}$ & $\mathrm{X}$ & $\mathrm{X}$ & $\mathrm{X}$ & $\mathrm{X}$ \\
\hline $\mathrm{DL}$ & $\mathrm{X}$ & $\mathrm{X}$ & $\mathrm{X}$ & $\mathrm{X}$ & $X$ & $\mathrm{X}$ \\
\hline NS & $\mathrm{X}$ & $\mathrm{X}$ & $\mathrm{X}$ & $\mathrm{X}$ & $\mathrm{X}$ & $\mathrm{X}$ \\
\hline TT & $X$ & & $\mathrm{X}$ & & & $\mathrm{X}$ \\
\hline ST & $\mathrm{X}$ & & $\mathrm{X}$ & & $\mathrm{X}$ & \\
\hline QP & $x$ & & $\mathrm{X}$ & $\mathrm{X}$ & $X$ & $\mathrm{X}$ \\
\hline FC & $x$ & $\mathrm{X}$ & $x$ & $\mathrm{X}$ & $X$ & \\
\hline PER & & $\mathrm{X}$ & & & $X$ & $x$ \\
\hline NFR & & $X$ & $X$ & & & \\
\hline LS & $\mathrm{X}$ & $\mathrm{X}$ & & $\mathrm{X}$ & & \\
\hline TC & $\mathrm{X}$ & $x$ & & $\mathrm{X}$ & $\mathrm{X}$ & $\mathrm{X}$ \\
\hline VC & & $X$ & & $\mathrm{X}$ & & \\
\hline LoC & & & $\mathrm{X}$ & & & \\
\hline UT & & & $\mathrm{X}$ & & & $\mathrm{X}$ \\
\hline DIC & & $\mathrm{X}$ & & $X$ & & \\
\hline PDP & & & & $x$ & & \\
\hline $\mathrm{V}$ & $\mathrm{X}$ & & & & $\mathrm{X}$ & $x$ \\
\hline
\end{tabular}

ND: Number of destinations, VC: Vehicle capacity, QV: Quantity of vehicles, TF: Type of fleet, D: Demand, DIS: Distance between points, DL: Destination location, NS: Number of sources, TT: Transport time, ST: Service time, QP: Quantity per product, FC: Fixed cost, PER: Perishability, NFR: Number of feasible routes, LS: Location of source, TC: Transport cost, VC: Variable cost, of load, LoS: Loading time, UT: Unloading time, DIC: Damaged inventory cost, PDP: Product damage penalty, V: Speed.

Table 1. Variables and Parameters

Amorim, Günther and Almada-Lobo (2012) studied the relationship between cost-freshness using a multiobjective model, time and cost related to the Euclidean distance of the connected vertices. However, they assume maximum 
freshness when the vehicle leaves the warehouse and a strict time window for delivery. They represent the useful life of the products within the order of the customer that deteriorates the most, therefore, all the other products still have some remaining useful life when they are delivered. Likewise, Song and Ko (2016) study the VRP in refrigerated vehicles for perishable foods, starting from a maximum delivery time and customer satisfaction measured in freshness.

In the review of the literature it was identified that in the problem of VRP for perishables in mega cities, the direct effect of delivery time on the perishability function of fruits has not been considered. This research seeks to answer the following research questions. How would it be considered the effect of congestion in the process of fruit delivery routing? And, how does the perishability of fruits affect the routing problem?

\section{Methodolody}

A mathematical model was formulated based on two classical models: the three-index vehicle flow model proposed by Golden et al. (1984) and the time window model proposed by Cordeau et al. (1999). It uses the flow variable to control the amount of each fruit arriving to each node and the time variable to define fruit waste or loss depending on the time and type of fruit.

\subsection{Methodology Design of the Model for Fruit Delivery Routing}

Next, the indexes, parameters, decision variables, constraints and objective function of the designed model are presented in detail.

Sets:

T: Type of vehicles

$\mathrm{V}=\{0,1,2 \ldots,|\mathrm{V}|\}:$ All nodes

$\mathrm{V}^{\prime}=\mathrm{V} \backslash\{0\}:$ Consumers

$\mathrm{K}=\{1,2 \ldots,|\mathrm{K}|\}:$ All vehicles

$\mathrm{H}=\{1,2 \ldots,|\mathrm{H}|\}:$ Fruits

Decision variable:

$\mathrm{x}_{\mathrm{i}, \mathrm{j}, \mathrm{k}}$ : Binary variable equal to 1 if the $\operatorname{arc}(\mathrm{i}, \mathrm{j})$ is crossed with the type of vehicle $\mathrm{k}$ and 0 otherwise $(i \in V, j \in V, k \in$ $K: i<>j)$

$\mathrm{y}_{\mathrm{i}, \mathrm{h}}$ : Variable indicating the amount of fruit $\mathrm{h}$ carried by the truck when it arrives to node $\mathrm{i}(\mathrm{i} \in \mathrm{V}, \mathrm{h} \in \mathrm{H})$

$t_{i}:$ Time of arrival to node i. $(i \in V)$.

$\operatorname{tr}_{k}$ : Time for return of vehicle $k$ to node zero

Parameters:

HL: Working hours. [h]

$a_{i, j}$ : Distance between node $i$ and $j ; i$ and $j \in V 0[K m]$

$\mathrm{d}_{\mathrm{i}, \mathrm{h}}$ : Demand of node $\mathrm{j}$, of fruit $\mathrm{h}[\mathrm{Kg}]$

$\mathrm{q}_{\mathrm{k}}$ : Capacity of vehicle $\mathrm{k}[\mathrm{Kg}]$

$c_{k}$ : Fixed cost of operation by vehicle [\$]

$\mathrm{cv}_{\mathrm{k}}$ Variable cost of vehicle $\mathrm{k}\left[\frac{\$}{\mathrm{Km}}\right]$

$\mathrm{cp}_{\mathrm{h}}$ : Cost of lost fruit $\mathrm{f}\left[\frac{\$}{\mathrm{Kg}}\right]$

$\mathrm{ph}_{\mathrm{h}}$ : Percentage of fruit $\mathrm{h}$ that is damaged per hour $\left[\frac{\%}{\mathrm{H}}\right]$

$\mathrm{s}_{\mathrm{i}}$ : Service time of node i $[\mathrm{H}]$

$\mathrm{v}_{\mathrm{k}}$ : Average speed of vehicles $\mathrm{k}\left[\frac{\mathrm{Km}}{\mathrm{H}}\right]$

$\mathrm{q}^{|\mathrm{k}|}$ : Vehicle with greater capacity $[\mathrm{Kg}]$ 
Equations:

$$
\begin{aligned}
& \min Z=\left(\sum_{\mathrm{i} \in \mathrm{V}} \sum_{\mathrm{j} \in \mathrm{V} / \mathrm{i} \neq \mathrm{j}} \mathrm{a}_{\mathrm{i}, \mathrm{j}} \sum_{\mathrm{k} \in \mathrm{K}} \mathrm{c} \mathrm{v}_{\mathrm{k}} \mathrm{x}_{\mathrm{i}, \mathrm{j}, \mathrm{k}}\right)+\sum_{\mathrm{k} \in \mathrm{K}} \mathrm{c}_{\mathrm{k}} \sum_{\mathrm{j} \in \mathrm{V}^{\prime}} \mathrm{x}_{0, \mathrm{j}, \mathrm{k}}+\sum_{\mathrm{h} \in \mathrm{H}} \sum_{\mathrm{j} \in \mathrm{V}^{\prime}} \mathrm{d}_{\mathrm{j}, \mathrm{h}} * \mathrm{ph} \mathrm{h}_{\mathrm{h}} *\left(\mathrm{t}_{\mathrm{j}}\right) * \mathrm{cp}_{\mathrm{h}}, \\
& \sum_{\mathrm{k} \in \mathrm{K}} \sum_{\mathrm{j} \in \mathrm{V} / \mathrm{j} \neq \mathrm{i}} \mathrm{x}_{\mathrm{i}, \mathrm{j}, \mathrm{k}}=1, \quad \forall \mathrm{i} \in \mathrm{V}^{\prime} \\
& \sum_{i \in V / i \neq j} x_{i, j, k}-\sum_{i \in V / i \neq} x_{j, i, k}=0, \quad \forall j \in V, k \in K \\
& \mathrm{y}_{\mathrm{i}, \mathrm{h}}+\mathrm{q}^{|\mathrm{K}|} *\left(1-\mathrm{x}_{\mathrm{i}, \mathrm{j}, \mathrm{k}}\right) \geq \mathrm{d}_{\mathrm{ih}} *\left(\mathrm{x}_{\mathrm{i}, \mathrm{j}, \mathrm{k}}\right)+\mathrm{d}_{\mathrm{i}, \mathrm{h}} * \mathrm{ph}_{\mathrm{h}} *\left(\mathrm{t}_{\mathrm{i}}\right)+\mathrm{y}_{\mathrm{j}, \mathrm{h}}, \\
& \forall \mathrm{j} \in \mathrm{V}, \mathrm{i} \in \mathrm{V}^{\prime} / \mathrm{i} \neq \mathrm{j}, \mathrm{h} \in \mathrm{H}, \mathrm{k} \in \mathrm{K} \\
& \sum_{h \in H} y_{i, h} \leq \sum_{j \in V / i \neq j} \sum_{k \in K} x_{j, i, k} * q_{k}, \forall i \in V^{\prime} \\
& \mathrm{t}_{\mathrm{j}} \geq \mathrm{t}_{\mathrm{i}}+\mathrm{s}_{\mathrm{i}}+\left(\sum_{\mathrm{k} \in \mathrm{K}} \mathrm{x}_{\mathrm{i}, \mathrm{j}, \mathrm{k}} * \frac{\mathrm{a}_{\mathrm{i}, \mathrm{j}}}{\mathrm{v}_{\mathrm{k}}}\right)-\mathrm{HL} *\left(1-\sum_{\mathrm{k} \in \mathrm{K}} \mathrm{x}_{\mathrm{i}, \mathrm{j}, \mathrm{k}}\right), \quad \forall \mathrm{i} \in \mathrm{V}^{\prime}, \mathrm{j} \in \mathrm{V}^{\prime} \neq \mathrm{j} \\
& \mathrm{t}_{\mathrm{j}}>=\left(\sum_{\mathrm{k} \in \mathrm{K}} \mathrm{x}_{0, \mathrm{j}, \mathrm{k}} * \frac{\mathrm{a}_{0, \mathrm{j}}}{\mathrm{v}_{\mathrm{k}}}\right)-\mathrm{HL} *\left(1-\sum_{\mathrm{k} \in \mathrm{K}} \mathrm{x}_{0, \mathrm{j}, \mathrm{k}}\right), \quad \forall \mathrm{j} \in \mathrm{V}^{\prime} \\
& \sum_{\mathrm{j} \in \mathrm{V}^{\prime}} \mathrm{x}_{0, \mathrm{j}, \mathrm{k}} \leq 1, \quad \forall \mathrm{k} \in \mathrm{K}, \\
& \operatorname{tr}_{\mathrm{k}} \geq \mathrm{t}_{\mathrm{i}}+\mathrm{s}_{\mathrm{i}}+\left(\mathrm{x}_{\mathrm{i}, 0, \mathrm{k}} * \frac{\mathrm{a}_{\mathrm{i}, 0}}{\mathrm{v}_{\mathrm{k}}}\right)-\mathrm{HL} *\left(1-\mathrm{x}_{\mathrm{i}, 0, \mathrm{k}}\right), \forall \mathrm{i} \in \mathrm{V}^{\prime}, \mathrm{k} \in \mathrm{K}
\end{aligned}
$$

The objective function, Equation (1), is made up of 3 cost components: The variable cost $\mathrm{cv}_{\mathrm{k}}$, which is determined by the distance travelled $a_{i, j}$ and the route each vehicle conformed by the sum of the arcs $\mathrm{x}_{\mathrm{i}, \mathrm{j}, \mathrm{k}}$. The fixed cost $\mathrm{c}_{\mathrm{k}}$ is given by the number of vehicles used. Concerning the cost of fruit that is damaged while being transported, the amount of fruit damaged $\mathrm{d}_{\mathrm{j}, \mathrm{h}} * \mathrm{ph}_{\mathrm{h}}$ depends on the time traveled at the time of delivery, $\mathrm{t}_{\mathrm{j}}$.

Equation (2) guarantees that only a single vehicle leaves from each node i, to a single next node $j$, except the origin. Equation (3) guarantees that the vehicle entering node $\mathrm{j}$ is the same one that leaves that node, for all nodes except the origin. Equation (4) guarantees that the quantity of fruit $h$ that reaches node $i$ is greater than that which leaves node $j$ when $j$ is after $i$, adding the waste in $i$ and the demand in $i$; this is calculated for each vehicle.

Equation (5) indicates that the amount of all fruits arriving at node $i$ is less than or equal to the capacity of the vehicle carrying them. Equation (6) guarantees that the time of arrival to node $j$, when going from $i$ to $j$, for $i \neq 0$ is greater than the time of arrival to $i$, adding the service time at $\mathrm{i}$ and the travel time from $\mathrm{i}$ to $\mathrm{j}$ in vehicle $\mathrm{k}$.

Equation (7) ensures that the time of arrival to node j, when going from 0 to $j$, is greater than the travel time from 0 to $\mathrm{j}$ in vehicle $\mathrm{k}$; vehicles are assumed to leave at zero node. Equation (8) guarantees that each vehicle only can go to one node from its origin. Equation (9) guarantees that the time of arrival to node 0 , when transporting from $i$ to 0 , for $i \neq 0$ is greater than the time of arrival to $i$, adding the service time at $i$ and the time of moving from $i$ to 0 in 
vehicle $\mathrm{k}$. Since the zero node is the only one to which more than one vehicle arrives, the arrival time for each vehicle is specified at this node.

\subsection{The Model's Strategy of Solution}

The proposed model was used to find the optimal solution for twenty nodes, six vehicles and six types of fruit using AMP®. However, it was applied to a factual problem that exceeds this number of nodes, for which results were not obtained in considerable time to the context of the problem; therefore, it was developed in two phases.

A first phase of clustering of nodes, based on a modified p-median model, then the routing model was solved for each of the clusters. The proposal is presented in Figure 1.

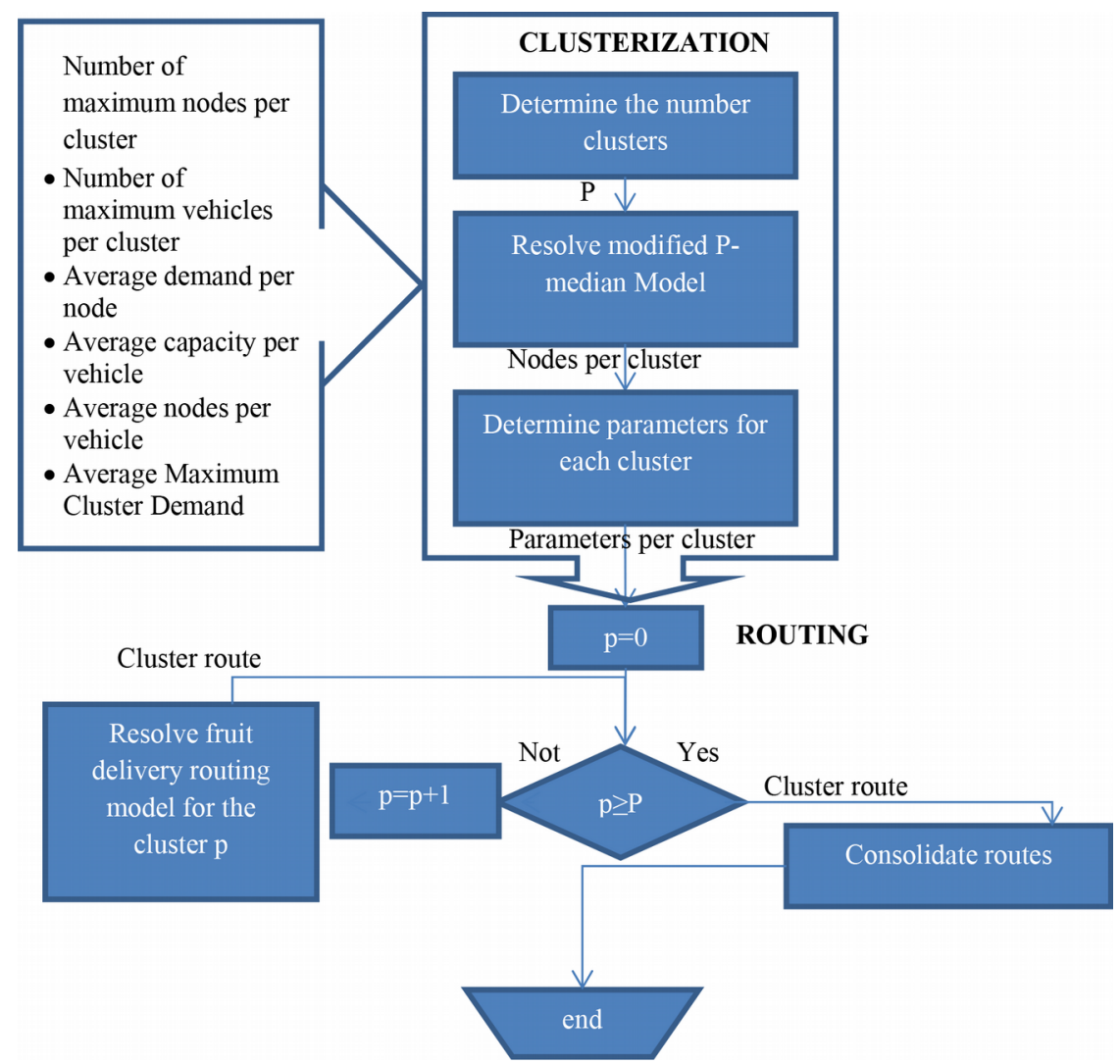

Figure 1. Phases and stages for finding the optimal solution using the model Clustering

The clustering phase was made in the following stages.

\subsubsection{Number of Clusters}

The first stage was the definition of a number of clusters that would allow considerable computing time. From the previous analysis of the fruit routing model and taking into account the daily planning horizon of the model, a number of nodes, (maxno) and of vehicles (maxve) were established.

Taking into account the heterogeneity on the vehicle fleet and the fruit demand of each node, the average capacity of each vehicle (qpv) and the average demand of each node (dpn) were determined. With these parameters, the maximum average demand per cluster (dmpc) was established, Equation (10).

$$
\operatorname{Dmpc}=\min (\operatorname{maxno} * d p n, \operatorname{maxve} * \mathrm{qpv})
$$

Then the number of clusters $\mathrm{P}$ was established, based on the average maximum demand per cluster and the total demand (dt) Equation (11): 


$$
\mathrm{P}=\left\lceil\frac{\mathrm{dt}}{\mathrm{dmpc}}+1\right\rceil
$$

\subsubsection{Clustering Model: Modified P-median}

Since time of the route is relevant for the lost amount of perishable food in the mega-cities, a modification has been made to the model p-median, with the purpose of finding groups of nodes with distance and loads balanced, and with it, a preliminary balance in the journey times, which is presented below.

Sets:

$\mathrm{V}=\{0,1,2 \ldots,|\mathrm{V}|\}:$ Nodes and/or potential clusters

$\mathrm{V}^{\prime}=\{1,2 \ldots,|\mathrm{V}|\}:$ Clients and/or potential clusters

$\mathrm{H}=\{1,2 \ldots,|\mathrm{H}|\}:$ Fruits

Decision variables:

$B_{i, c c}$ : Binary variable equal to 1 if node $i$ is assigned to cluster $j$.

$\mathrm{DC}_{\mathrm{cc}}$ : Total distance in the cluster cc

DM: Distance of the cluster with greater distance

Parameters:

P: Number of clusters to form

$\mathrm{d}_{\mathrm{i}, \mathrm{h}}$ : Demand in node $\mathrm{i}$ of fruit $\mathrm{h}$

dt: Total demand.

$a_{i, c}$ : Distance from node $i$, to cluster cc.

Equations:

$$
\begin{gathered}
\min D M A X=D M \\
D M \geq D_{C C} \quad \forall C C \in V \\
\sum_{c c \in V} B_{i, c c}=1, \quad \forall i \in V^{\prime} \\
\sum_{c c \in V} B_{0, c c}=P \\
\sum_{i \in V^{\prime} h \in H} B_{i, c c} * d_{i, h} \leq\left[\frac{d t}{P} * 1.2\right] * B_{c c, c c} \quad \forall i \in V \\
B_{i, c c c} \leq B_{c c, c c}, \quad \forall c c \in V, i \in V \\
\sum_{c c \in V} B_{c c, c c}=P \\
\sum_{i \in V / i \neq c c} B_{i, c c} * a_{i, c c}=D C_{c c}, \quad \forall c c \in V
\end{gathered}
$$


Equation (12) represents the linearized objective function. It seeks to minimize the distance of the cluster with maximum distance, which represents a minimax. The linear form is obtained with Equation (12) and (13). Equation (14) ensures that each node, excluding the source node, is assigned to a single cluster, and (15) ensures that all clusters include the source node. Equation (16) ensures that the demand served by the clusters does not exceed $20 \%$ of the average demand. Equation (17) and (18) allow the indicated cluster number to be opened and nodes assigned only to open clusters. On the other hand, Equation (19) allows determining the total distance in each cluster.

\subsubsection{Parameters for each Cluster}

With the results of the clustering, and starting from variable B_(i,cc), the list and the number of nodes of each cluster, including the source, were established. For each cluster the distance matrix between their nodes, the demand of each of their nodes and the service times within them were established.

\subsubsection{Routing}

The fruit delivery routing model (section 2.1) was run for each of the clusters, with their respective parameters updated. This involved modifying the set of nodes as follows:

$$
\mathrm{V}_{\mathrm{cc}}=\left\{0,1,2 \ldots,\left|\mathrm{V}_{\mathrm{cc}}\right|\right\}
$$

Where $\mathrm{V}_{\mathrm{cc}}$ represents the cluster nodes cc, they are re-enumerated from the source to the number of nodes in the cluster. When running the fruit delivery model in each cluster, the routes were consolidated. Finally, the nodes were numbered with their original indexes for the definitive determination of the routes.

\section{Results and Discussion}

In order to apply the complete model, a base of 21 nodes, 6 vehicles and 6 types of fruit was used. The data were obtained in the city of Bogotá during the years 2015 and 2016, the fruit is sent from the main wholesale center of commerce, Corabastos to small shopkeepers located in different neighborhoods (Orjuela-Castro, Calderón \& Buitrago, 2006: page 400), (Orejuela-Castro, Diaz-Gamez \& Bernal-Celemin, 2017: pages 225-237). The model was implemented in AMPL and the Gurobi solver was used in the NEOS Server page. The results for the optimal solution of the routes are presented in Table 2 .

We assume function of continuous decay for the VRP model, an approach not used into the highly perishable foods, what allowed to extend this modeled to other products. Our model beats the models proposals for Cheng, Hsueh and Chang (2009), Amorim et al. (2012) and Song \& Ko (2016), to consider deteriorate of food as continuous decay function. Those researchers use the soft or strict time windows, while our model use the percentage of fruit that is damaged per hour. This allows that the amount of fruit damaged depends on the time traveled at the time of delivery. As observed in the objective function, the cost of fruit that is damaged is associated to transport. Likewise in a constraint, Equation (4), the loss derived of the function of continuous decay is contemplated. Also the effect of congestion is included.

\begin{tabular}{|c|c|c|c|r|r|r|r|}
\hline Vehicle & Capacity & Speed & Route & Y0 & \multicolumn{1}{|c|}{$\begin{array}{c}\text { Variable } \\
\text { Cost }\end{array}$} & $\begin{array}{c}\text { Fixed } \\
\text { Cost }\end{array}$ & $\begin{array}{c}\text { Loss Cost } \\
\text { Fruit }\end{array}$ \\
\hline 2 & 2 & 60 & $0-1-9-0$ & 1.11 & 38 & 127.8 & 131.01 \\
\hline 3 & 1 & 60 & $0-11-0$ & 825 & 13,5 & 127.8 & 129.702 \\
\hline 4 & 2 & 60 & $0-20-3-19-10-0$ & 1.941 & 138 & 160.9 & 165.043 \\
\hline 5 & 2 & 60 & $0-16-17-0$ & 1.331 & 72 & 160.9 & 164.318 \\
\hline 6 & 4 & 60 & $0-18-2-5-14-13-6-4-15-8-$ & 702 & 160.9 & 169.598 \\
\hline Total & 11 & & $7-12-0$ & 9.137 & 913 & 738.3 & 759.67 \\
\hline
\end{tabular}

Table 2. Results 


\section{Conclusions}

A last-mile logistics strategy to manage delivery routes for fresh fruits in mega-cities, considering the effect of congestion through travel time in the perishability function is proposed. The model uses a flow variable to control the amount of each fruit that arrives to each node and a variable time to establish the loss of fruit that depends on the time according to the type of fruit, as function of continuous decay. The problem of routing for deliveries of perishable foods considers the fixed cost of transport, the variable cost per distance travelled and the cost per loss of fruit dependent on the transport time. The linear model allows capturing the costs without multiplying by the flow variables, likewise the complexity of the problem decreases with the formation of clusters.

The model is applied in a mega-city for the case of 6 perishable fruits and includes restrictions that allow approaching this problem in a way that is closer to reality. On the one hand, it takes into account the perishability of the fruit with regard to the time of travel and on the other; it determines the routes taking into account the capacity of the vehicle and the transport times for highly perishable products. If the effect of congestion is not considered in the time, the routing would concentrate on taking the shortest routes, regardless of whether they may be more delayed, which would generate more fruit lost.

The results show the need to study, on the one hand the fruit losses and on the other the efficiency, which raises the need for a multi-objective model, as future research.

\section{Declaration of Conflicting Interests}

The authors declared no potential conflicts of interest with respect to the research, authorship, and/or publication of this article.

\section{Funding}

This work was supported by Faculty of engineering Universidad Distrital Francisco José de Caldas, Colombia; the School of Industrial Engineering from Universidad del Valle, Colombia; Faculty of engineering from Universidad Nacional, Colombia.

\section{References}

Amorim, P., Günther, H.O, \& Almada-Lobo, B. (2012). Multi-objective integrated production and distribution planning of perishable products. International Journal of Production Economics, 138, 89-101. https://doi.org/10.1016/j. cie.2013.11.006

Chen, H.K., Hsueh, C.F., \& Chang, M.S. (2009). Production scheduling and vehicle routing with time windows for perishable food products. Computers \& operations research, 36(7), 2311-2319. https://doi.org/10.1016/j.cor.2008.09.010

Cheng, J.Y.K., \& Lo, I.M.C. (2016). Investigation of the available technologies and their feasibility for the conversion of food waste into fish feed in Hong Kong. Environmental Science and Pollution Research, 23(8), 7169-7177. https://doi.org/10.1007/s11356-015-4668-3

Cordeau, F., Desaulniers, G., Desrosiers, J., Solomon M., \& Soumis, F. (1999). The VRP with time windows. Technical Report Cabiers du GERAD G, 99-13.

Golden, B., Assad, A., Levy, L., \& Gheysens, F. (1984). The fleet size and mix vehicle routing problem. Computers \& Operations Research, 11, 49-66. https://doi.org/10.1016/0305-0548(84)90007-8

Gong, W., \& Fu, Z. (2010). ABC-ACO for Perishable Food Vehicle Routing Problem with Time Windows. In International Conference on Computational and Information Sciences. https://doi.org/10.1109/ICCIS.2010.311

Gonzalez, L.E.C., Adarme J.W., \& Orjuela, C.J.A. (2015). Stochastic mathematical model for vehicle routing problem in collecting perishable products. Dyna, 82(189), 199-206. http://dx.doi.org/10.15446/dyna.v82n189.48549

Govindan, K., Jafarian, A., Khodaverdi, R., \& Devika, K. (2014). Two-echelon multiple-vehicle location-routing problem with time windows for optimization of sustainable supply chain network of perishable food. International Journal of Production Economics, 152, 9-28. https://doi.org/10.1016/j.ijpe.2013.12.028

Graizbord, B. (2007) Megaciudades, globalización y viabilidad urbana, Investigaciones. Geográficas, 63(20), 125-140. 
Jabali, O., Van Woensel, T., \& De Kok, A. (2012). Analysis of travel times and CO2 emissions in time-dependent vehicle routing. Production and Opereration Management, 21(6), 1060-1074. https://doi.org/10.1111/j.19375956.2012.01338.x

Kande, S., Prins, C., Belgacem, L., \& Redon, B. (2015). Local Search Based Metaheuristics for Two-Echelon Distribution Network with Perishable Products. Operations Research and Enterprise Systems, 577, $212-231$. https://doi.org/10.1007/978-3-319-27680-9_13

Khalili-Damghani, K., Abtahi., A., \& Ghasemi, A.R. (2015) A New Bi-objective Location-routing Problem for Distribution of Perishable Products: Evolutionary Computation Approach. Journal of Mathematical Modelling and Algorithms in Operations Research, 14(3), 287-312. https://doi.org/10.1007/s10852-015-9274-3

Orjuela-Castro, J. A., Sepulveda-García, D.A., \& Ospina-Contreras, I.D. (2016). Effects of Using Multimodal Transport over the Logistics Performance of the Food Chain of Uchuva. In Figueroa-García, J., López-Santana, E., Ferro-Escobar, R. (Eds.), Applied Computer Sciences in Engineering. WEA 2016. Communications in Computer and Information Science (657). Cham: Springer. https://doi.org/10.1007/978-3-319-50880-1_15

Orjuela-Castro, J.A., Calderón, M.E., \& Buitrago, H.S. (2006). La cadena agroindustrial de frutas. Bogotá D.C: Universidad Distrital Francisco José de Caldas p. 400.

Orjuela-Castro, J.A., Diaz-Gamez, G.L., \& Bernal-Celemin, M.P. (2017). Model for Logistics Capacity in the Perishable Food Supply Chain. Applied Computer Sciences in Engineering. WEA 2017. Communications in Computer and Information Science (742, 225-237). https://doi.org/10.1007/978-3-319-66963-2_21

Osvald, A., \& Stirn, L.Z. (2008). A vehicle routing algorithm for the distribution of fresh vegetables and similar perishable food. Journal of Food Engineering, 85(2), 285-295. https://doi.org/10.1016/j.jfoodeng.2007.07.008

Rahimi, M., Baboli A., \& Rekik, Y. (2014) A bi-objective inventory routing problem by considering customer satisfaction level in context of perishable product, in In Computational Intelligence in Production and Logistics Systems (CIPLS), 2014 IEEE Symposium on. http://doi.org/10.1109/CIPLS.2014.7007166

Rocha-Medina, L.B., González-La Rotta, E.C., \& Orjuela-Castro, J.A. (2011). Una revisión al estado del arte del problema de ruteo de vehículos: Evolución histórica y métodos de solución. Ingeniería, 16(2), 35-55. https://doi.org/10.14483/issn.2344-8393

Shamsi, A., Raisi, A., \& Aftab, M. (2014). Pollution-Inventory Routing Problem with Perishable Goods. In Logistics Operations, Supply Chain Management and Sustainability (585-596). Springer. https://doi.org/10.1007/978-3-319-07287-6

Song, B.D, \& Ko, Y.D. (2016). A vehicle routing problem of both refrigerated-and general-type vehicles for perishable food products delivery. Journal of Food Engineering, 169, 61-71.

https://doi.org/10.1016/j.jfoodeng.2015.08.027

Soysal, M., Bloemhof-Ruwaard J.M., Haijema R., \& van der Vorst, J.G.(2015). Modeling an Inventory Routing Problem for perishable products with environmental considerations and demand uncertainty. International Journal of Production Economics, 164, 118-133. https://doi.org/10.1016/j.ijpe.2015.03.008

Thomson, I., \& Bull, A. (2001). La congestión del tránsito urbano: causas y consecuencias económicas y sociales. Revista de la CEPAL, 76, 109-121.

Zhang, Y., \& Chen, X.D. (2014). An Optimization Model for the Vehicle Routing Problem in Multi-product Frozen Food Delivery. Journal of Applied Research and Technology, 12(2), 239-250. https://doi.org/10.1016/S1665-6423(14)72340-5

Journal of Industrial Engineering and Management, 2019 (www.jiem.org)

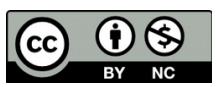

Article's contents are provided on an Attribution-Non Commercial 4.0 Creative commons International License. Readers are allowed to copy, distribute and communicate article's contents, provided the author's and Journal of Industrial Engineering and Management's names are included. It must not be used for commercial purposes. To see the complete license contents, please visit https://creativecommons.org/licenses/by-nc/4.0/. 